\title{
Managing the climate change impact on the Slovenian coast
}

\author{
I. Jurinčič ${ }^{1}$, D. Ogrin ${ }^{2}$, T. Brezovec ${ }^{1} \&$ Z. Kribel ${ }^{1}$ \\ ${ }^{I}$ Faculty of Tourism Studies Portorož - Turistica, \\ University of Primorska, Slovenia \\ ${ }^{2}$ Department of Geography, Faculty of Arts, University of Ljubljana, \\ Slovenia
}

\begin{abstract}
Attitudes toward the natural environment and its uses are becoming an important issue of global concern. Climate change and associated natural disasters demand different practices in the use of natural and environmental goods in a more longterm sustainable way, reducing the damage of different economic activities. Among such activities are also those of leisure and tourism where the focus should be on sustainable tourism development in balance with economic interests and ecological requirements. This paper presents some results of recent research on historical tourism and meteorology data for the coastal region of Slovenia. A regression analysis shows that tourist arrivals to the Slovenian coast depend on seasonal temperatures and rainfall quantity. However, further in-depth research is necessary to explain the degree of direct influence of climate change to tourism on the Slovene coast.
\end{abstract}

Keywords: coastal region, tourism demand, weather factors, regression analysis, Slovenia.

\section{Introduction}

Climate change and associated natural disasters demand different practices in the use of natural and environmental goods in a more long-term sustainable way, reducing the damage of different economic and human activities [1-4]. The group of experts for climate change at the United Nations [5] argue that global climatic changes will have a significant effect on the tourism industry. Since the impact of climate change on tourism differs by regions, each region should 
assess how the climatic changes might affect its tourism resources. This paper concentrates on the coastal region of Slovenia. The coast is the most important tourism area with a $25 \%$ share of tourism in terms of tourist arrivals, nights spent and tourism income.

\section{Long term climate changes}

Obtaining quality long-term data on the climate for the coastal area of Slovenia is rather difficult. During the last century, this area has been subject to frequent changes of political borders. As a consequence, climate monitoring was performed by various Austrian, Italian, Yugoslav and Slovenian institutions, each collecting data during a specific period in time. Collection and consolidation of data from the various sources necessary to form a long-term data series for the analysis is almost impossible due to changes in methodology, frequency and accuracy of measurements. However, some available data show long-term climate changes in this region. The analysis of air temperatures for the summer months during the period 1850 - 2002 for the wider Gulf of Triest area reveals a growing trend in average air temperature of about $0.3^{\circ} \mathrm{C}$ per 100 years [6]. A more reliable and geographically focused time series is available for the period after 1951. This data also shows rising average air temperatures. In Portorož, the largest tourism destination on the Slovenian coast, the average summer temperature has grown by $0.6^{\circ} \mathrm{C} \pm 0.5^{\circ} \mathrm{C}$ during the $1951-2000$ period. Rising temperatures, longer periods of sunshine, less rainfall and rainfall concentration in autumn are signs of 'Mediterranization' of the climate on the Slovenian coast.

\section{Extreme temperatures}

Higher air and local sea temperature as well as the increasing number of hot days (days with the maximum daily temperature above $30^{\circ} \mathrm{C}$ ) are expected to have a positive influence on:

- a longer swimming season and desire for swimming at the seaside tourist resorts (comparable to the current situation e.g. in Spain and Greece) and in other swimming and spa tourism destinations in Slovenia (e.g. Pomurje and Posotelje), and

- $\quad$ better and improved supply and offers of thalassotherapy and climatic spa resorts in Slovenia. Due to the expected increase in demand, an increase of supply of these services in the coastal and mountain tourism regions is expected.

On the other hand, the rise of average temperatures will result in higher energy consumption. To mitigate this negative impact, it is expected that more effort will be put into:

- the control of energy consumption for air-conditioning devices;

- the improvement of insulation of tourist housing facilities;

- the introduction and improvement of energy saving measures and 
- the stimulation of use of renewable sources of energy such as solar energy, use of biomass, biogas and geo-thermal energy.

\section{Water shortage}

Less rain is expected to fall in the coastal area in Slovenia with at least the following implications:

- coastal and other water deficient areas of Slovenia will face a shortage of drinking water and water in general for irrigation, washing and similar uses;

- a change of landscape due to less green and more burnt yellow areas during the summer months;

- $\quad$ an increase in the danger of fires in nature.

Tourism regions with temporary water shortages (e.g. Istria and Karst) must introduce measures for drinking water savings and recycling of water wastes, to ensure adequate water quantity [7]. As an example, setting up a separate distribution system for recycled water enables its use for irrigation, toilet flushing, washing of public areas and similar, thus saving precious drinking water. Such systems may be installed during the construction or renovation of the tourism infrastructure (e.g. accommodation facilities, swimming and spa facilities, the public sewage system, etc.). In Slovenia, there are currently renovations and construction underway in hotels in Portorož, Bled, and other leading tourism destinations but none of them will install such a system. Investors claim higher present investment costs as the main reason for such attitude, neglecting long-term benefits in the form of lower operational costs (e.g. lower water and energy costs) and the potential increase of income and image (e.g. eco-conscious customers, market niches).

From the tourism destination standpoint, the introduction of a rational-use-ofwater approach would provide a spill over effect of good practices to other tourist providers as well as to the broad civil society and niche groups with an efficient message on its environmental and social responsibility for sustainable development [8]. Due to its high costs, the inclusion of such and similar measures for diminishing climate changes impact is expected to be primarily a strategy for larger investors in tourism in Slovenia (e.g. the Istrabenz Group, the Sava Group and some other leading tourism companies). However, smaller investors should also be stimulated to adopt such measures, even if at a smaller scale.

Water shortages during the summer season have already become a constant phenomenon in Istria and Dalmatia. The situation may be further worsened by fires (natural or intentionally ignited), as the lack of water affects firefighting (e.g. Dalmatia, Italy, Greece, Spain, etc.).

Besides the water supply, the energy supply is becoming another issue linked to expected climatic changes. Air conditioning systems, water pumps, lighting and other devices, which create a pleasant ambience, have become standard in tourism destinations and suppliers of electric power already find it difficult to cope with the increasing use of electricity during the tourist season. 


\section{Research results}

This paper tries to assess how climate factors affect tourism demand on the Slovenian coast. The average, minimum and maximum air temperatures, rainfall quantity, and seawater temperatures were analysed and compared with tourism demand data (expressed in overnight stays). The research was focused on Portorož, a tourist destination on the Slovenian coast. Climatic data were obtained from the Slovene Environment Agency ARSO and the Hydro Meteorological Institute of Slovenia [9]. Tourism data were collected by the Statistical Office of the Republic of Slovenia. Physical and aggregated climatic data were compared with tourism demand data. The period under study was from 1950 to 2007. The study was carried out in July and August 2007.

\subsection{Sea surface temperature}

We elaborated daily sea surface temperatures for the period from January 11960 to December 31 1991. The water thermometer was situated at the site ESEAS ID Koper, Koper 360. The thermometer collected the temperature three times a day. From January 11992 the station was moved to ESEAS ID: KOPE at the Port of Koper H01. The new automatic sensor thermometer collected temperature data each hour with continuous recording. Table 1 summarizes some temperatures from various historical periods.

Table 1: July monthly sea surface temperatures in degrees Celsius.

\begin{tabular}{|c|c|c|c|}
\hline & Minimal temp. $\left[{ }^{\circ} \mathrm{C}\right]$ & Average temp. $\left[{ }^{\circ} \mathrm{C}\right]$ & $\begin{array}{c}\text { Maximum temp. } \\
{\left[{ }^{\circ} \mathrm{C}\right]}\end{array}$ \\
\hline $1960-1969$ & 18.6 & 23.8 & 27.9 \\
\hline $1970-1979$ & 17.2 & 23.5 & 26.5 \\
\hline $1980-1989$ & 19.3 & 23.8 & 28.0 \\
\hline $1990-1991$ & 21.4 & 23.5 & 24.6 \\
\hline $1992-2004$ & 19.3 & 22.7 & 24,8 \\
\hline July 312007 & 22.6 & 22.3 & 26.8 \\
\hline
\end{tabular}

On July 31 2007, the temperatures were minimum 22.6, average 25.3, and maximum 26.8 degrees Celsius. All of them are higher than appropriate sea temperatures during the periods in Table 1. A linear regression shows the average sea surface temperature growth of about $0.4^{\circ} \mathrm{C}$ per year.

\subsection{Dependency of tourism demand on weather factors}

We compared local air temperatures and rainfall quantity with tourist arrivals to Portorož. The study was limited to the 1960 to 2002 time period and to warmer 
summer months from May to October that represent the high tourism season. The analysis could not be extended to the period beyond 2002 due to discontinuity of data collection from the Statistical Office of the Republic of Slovenia.

Figure 1 shows the number of overnight stays for each single month over the studied period. There are three distinct groups of months. First, the July - August pair, which represents the level of demand during the peak season with high temperatures. Second is the June - September pair, followed by the May October pair with lower air temperatures (pre- and post-season). Figure 1 clearly shows a changing pattern in demand after a 1991 drop that was the result of the independence war of Slovenia and is not caused by climate factors. Tourist demand in hot summer months is decreasing while the demand in other months is rising, thus creating a less distinctive peak season and de-seasoning of demand during the summer months.

Tourism data (number of overnight stays) were elaborated with SPSS together with the average monthly air temperatures, rainfall quantity data, and the number of days with temperatures higher than $25^{\circ} \mathrm{C}$ for the selected years and months. The variable correlations are shown in the Table 2.

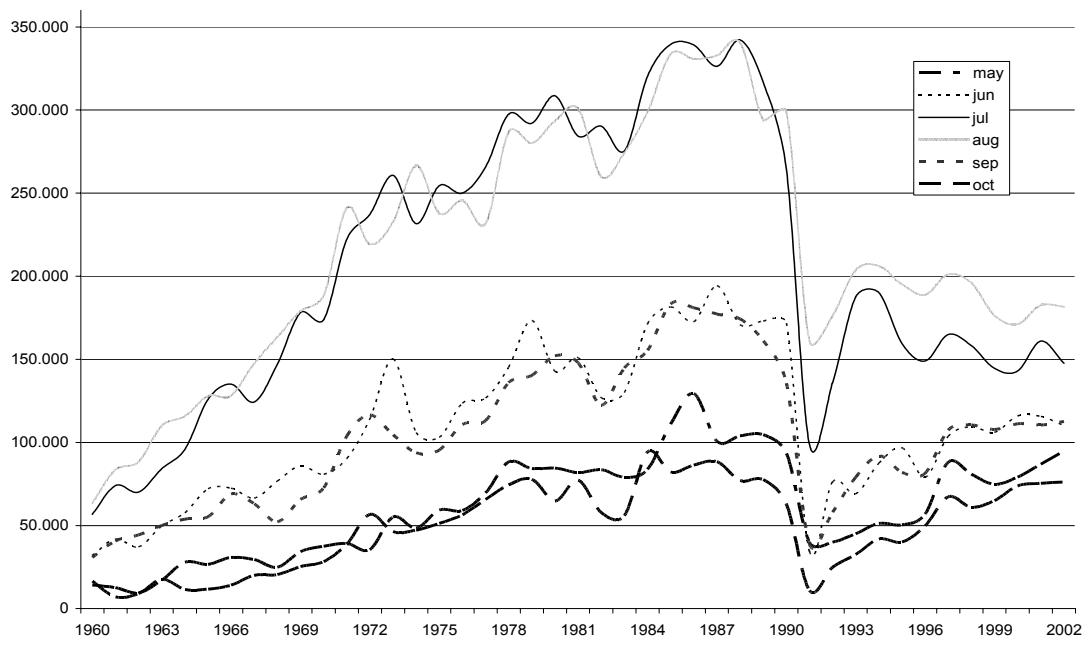

Figure 1: $\quad$ Number of overnight stays $1960-2002$ for the selected months.

A linear regression analysis was performed on the average monthly temperature and the monthly quantity of rainfall data with tourism stays as a dependent variable. The model explains about 45 percent of the total variance, and the F statistics has a value of 106 (Sig. 0.000). The amount of tourism demand in Portorož can be predicted through the following model:

Tourism stays $=-221415+17971 *$ AverageMonthlyTemperature $-17265 *$ RainfallQuantity. 
Since the average monthly temperatures already contain 'month' information, this calculation does not depend on the month or year.

Table 2: $\quad$ Correlations from SPSS 14.0.

\begin{tabular}{|ll|r|r|r|}
\hline & & AveTmpPO & \multicolumn{1}{|c|}{ RainMM } & \multicolumn{1}{c|}{ ArrivalsPO } \\
\hline AveTmpPO & Pearson Correlation & 1 &,$- 212^{* *}$ &, $674^{* *}$ \\
& Sig. (2-tailed) & &, 001 &, 000 \\
& $\mathrm{~N}$ & 258 & 258 & 258 \\
\hline RainMM & Pearson Correlation &,$- 212^{* *}$ & 1 &,- 156 \\
& Sig. (2-tailed) &, 001 & &, 012 \\
& $\mathrm{~N}$ & 258 & 258 & 258 \\
\hline ArrivalsPO & Pearson Correlation &, $674^{* *}$ &,- 156 & 1 \\
& Sig. (2-tailed) &, 000 &, 012 & \\
& $\mathrm{~N}$ & 258 & 258 & 258 \\
\hline
\end{tabular}

${ }^{* *}$. Correlation is significant at the 0.01 level (2-tailed).

Other tourism demand data, such as the number of arrivals, length of stay, reason for visit (leisure or business), means of transportation, accommodation supply, etc., should also be considered when assessing climate impact on tourism. However, lack of such data availability for the Slovenian coast has prevented an in-depth research and has limited this research to the above explained procedures.

\section{Conclusions}

As climate changes affect wider geographical areas, their residents and visitors, it is necessary to involve all stakeholders in minimising the negative effect of these changes for tourism. An all-inclusive, integrated approach to climate change response ensures greater effectiveness in tackling climate change issues without diminishing the benefits of tourism to the society. Such an approach demands each stakeholder make his contribution as follows.

The government should:

- prepare a strategy and introduce programmes to mitigate risks for tourism due to global climatic changes;

- $\quad$ stimulate the adoption of appropriate measures (e.g. by tax reductions, financial support, or low interest loans).

The municipalities should:

- adjust territorial plans and other development programs to outset expected climatic changes;

- $\quad$ support the use of public passenger traffic, sport activities, recreation, cultural life and social events;

- $\quad$ set up permanent monitoring of the environment, warming systems and information dissemination to citizens and enterprises. 
The tourism industry should:

- $\quad$ introduce rational use of natural and energetic resources [10];

- $\quad$ speed up environmental labelling of services and products (Ecolabel and similar programmes) [11];

- redesign their products;

- become more socially [12] and environmentally responsible (adoption of environmental memorandum, integrated advertising, sponsorships and donations), and

- introduce an integrated system of environmental management (ISO 14001, EMAS and similar).

Individuals and households should:

- $\quad$ take care of, and rationally use, natural resources;

- change their purchasing habits (purchase of agricultural and food products with traced geographical origin, choice of natural certified services and products of environmentally and socially responsible suppliers/producers);

- increase their quality of life by introducing healthy nutrition, and physical activities in nature;

- become more environmentally conscious and minimise their negative impact on the environment (e.g. recycling, calculation of own $\mathrm{CO} 2$ impact).

Tourists should:

- $\quad$ participate in environmental programmes at their destination (energy and water savings, recycling, etc.);

- opt for eco-friendly tourism providers;

- use more environmentally friendly means of transportation towards and at the destination.

\section{Acknowledgements}

We are particularly grateful to Mr. Marjan Bat and Ms. Mojca Robič, both from the Slovene Environment Agency ARSO.

\section{References}

[1] OECD. Climate Change in the European Alps: Adapting Winter Tourism and Natural Hazards Management, 1998.

[2] Gillmore, J.H., \& B. J. Pine. The Experience Economy. Boston, MA: Harvard Business School Press, 1999.

[3] Miller, G. The development of indicators for sustainable tourism: results of a Delphy survey of tourist researchers. Tourism Management 22, pp 351362, 2001.

[4] Getz, D. Event Studies: Theory, Research and Policy for Planned Events. Oxford: Elsevier Butterworth-Heinemann, 2007. 
[5] IPCC. Intergovernmental Panel on Climate Change, http://www.ipcc.ch, 2007.

[6] Ogrin, D., Seasonal changes of the air temperatures and precipitations in Ljubljana and Triest during 1851 - 2002. Dela 20, pp 115-131, 2003 (in Slovene).

[7] Jurincic, I., Carrying capacity assessment of Slovene Istria for tourism. Sustainable development and planning II, eds. A. Kungolos, C. A. Brebbia, and E. Beriatos, Southampton: WIT Press, pp 725-733, 2005.

[8] Gosar, A., \& Jurinčič, I., Sustainable tourism in the Alpe - Adria region: reality and goals. Dela, 19: pp 141-151, 2003.

[9] ARSO, Slovene Environment Agency. Slovene coast 1960 -2004 sea temperature data, 2007.

[10] Kasim, A., \& Scarlat, C., Business Environmental Responsibility in the Hospitality industry. Management 2, pp 5-23, 2007.

[11] Font, X., Environmental certification in tourism and hospitality: progress, process and prospects. Tourism Management 23, pp 197-205, 2002.

[12] Jowell, R., Roberts, C., Fitzgerald, R., and E. Gillian. 2007. Measuring Attitudes Cross-Nationally. London: SAGE Publications Ltd. 